Biografistyka Pedagogiczna

Rok 6 (2021) nr 1

ISSN 2543-6112; e-ISSN 2543-7399

DOI: 10.36578/BP.2021.06.24

\title{
Arleta Suwalska*
}

\section{Implikacje myśli pedagogicznej Johna Deweya w fińskiej edukacji ${ }^{1}$}

\section{The Implications of John Dewey's Pedagogical Thought in Finnish Education}

\begin{abstract}
John Dewey's pedagogical thought was an attempt to adapt the school to the needs and requirements of modern social life. John Dewey wanted to create a new type of education, which was at the same time against the traditional education system. In this article, biographical and pedagogical facts about John Dewey's life are intertwined with educational changes made based on them in basic Finnish education
\end{abstract}

Keywords: John Dewey, pedagogical implications, progressivism, pragmatism, experimentalism, upbringing, Finnish basic education, traditional school criticism, multidisciplinary learning modules.

* Arleta Suwalska (ORCID: oooo-0oo3-0713-8451) - dr, adiunkt na Wydziale Nauk o Wychowaniu (Zakład Pedagogiki Porównawczej) Uniwersytetu Łódzkiego, kontakt: arletasuwalska@o2.pl.

1 W artykule wykorzystano materiały zebrane podczas pobytu w programie Erasmus na University of Eastern Finland, Erasmus+, KA1Staff Mobility for Teaching Assignments w dniach 11-15 września $2017 \mathrm{r}$. 


\section{Wprowadzenie}

$\mathrm{Z}$

ałożenia reform edukacyjnych w Finlandii zostały oparte m.in. na filozofii i pedagogicznych doświadczeniach Johna Deweya, dlatego postaram się wykazać jej przenikanie i wpływ na zmianę w fińskiej szkole podstawowej. Demokratyczna wizja społeczeństwa wynikała $u$ amerykańskiego pedagoga z tradycji miejskich zebrań zwoływanych w Nowej Anglii, gdzie ludzie spotykali się, aby wspólnie rozwiązywać problemy i razem podejmować decyzje. Zarówno John Dewey (1859-1952), jak i jego rodzina aktywnie uczestniczyli w życiu społecznym i politycznym stanu Vermont, w którym pod koniec XIX wieku panował duch równości i braterstwa ${ }^{2}$. Idea społeczności zaangażowanej wywarła wpływ na kształt filozofii społecznej i edukacyjnej. Jego religijne wychowanie w ewangelickim kościele protestanckim zaś w dużym stopniu uformowało pogląd na sprawy społeczne i etyczne. Dewey dorastał pod wpływem „ewangelii społecznej” głoszącej, że „moralnym obowiązkiem człowieka jest praca nad reformą ziemskiego porządku, jak również działanie na rzecz polepszenia bytu społeczeństwa oraz naprawy stosunków społecznych"3.

Zmiany cywilizacyjne w Stanach Zjednoczonych początku XX wieku następowały w wyniku trzech rewolucji: społecznej, naukowej i przemysłowej. Pojawiały się stopniowo i powoli wpływały na stan permanentnej zmiany jako zasady społecznej. Postęp w reformach o charakterze społeczno-naukowo-przemysłowym opisał poeta Walt Whitman (1819-1892):

Spójrz, parostatki dymią poprzez moje śpiewy

Spójrz, w pieśniach moich ustawicznie przybijają i lądują emigranci [...]

2 Dewey po odbyciu studiów uniwersyteckich na uniwersytecie w Vermont kontynuował studia doktoranckie na Uniwersytecie Johna Hopkinsa wzorowanym na niemieckim modelu wyższej uczelni, w której nauczanie ściśle wiąże się z pracą badawczą. Po uzyskaniu doktoratu pracował na wydziale filozofii Uniwersytetu w Michigan, tam też habilitował się i wykładał w latach 1889-1894. W 1904 r. wyjechał z Chicago i zaczął pracować na wydziale filozofii Uniwersytetu w Columbii, gdzie nauczał do 1904 r. Cieszył się niezmiennie międzynarodową sławą. Jako filozof wykładał na uniwersytetach w Japonii, Chinach i Meksyku. Jego twórczość naukowa obejmuje ponad 1000 artykułów i książek, które wywarły olbrzymi wpływ na ogólnoświatową filozofię edukacji i społeczeństwa.

3 G. L. Gutek, Filozofia dla pedagogów, tłum. A. Kacmajor, A. Sulak, posł. B. Śliwerski, Gdańsk 2007, s. 84. 
Spójrz, walcowane machiny drukarskie z wieloma cylindrami; Spójrz, elektryczny telegraf, który siecią rozpina się nad kontynentem, Spójrz, jak przez głębie Atlantyku drgające tętno Ameryki dosięga Europy i dygocący puls Europy bezzwłocznej udziela odpowiedzi ${ }^{4}$.

Powstały wówczas takie partie polityczne: Nowa Wolność Woodrowa Wilsona i Nowy Nacjonalizm Theodore'a Roosevelta. Wyrażały przekonanie, że rozwijające się społeczeństwo korporacyjne powinno mieć narzucone pewne mechanizmy demokratyczne zapewniające dobrobyt wszystkim Amerykanom ${ }^{5}$. W takim klimacie polityczno-społecznym na początku XX wieku w Stanach Zjednoczonych narodził się progresywizm jako ruch postępowy, który silnie się zaznaczył w polityce amerykańskiej.

Jednak początków progresywizmu należy szukać znacznie wcześniej, bo w XVIII wieku, w epoce oświecenia. Progresywiści, podobnie jak teoretycy „ery rozumu", byli rzecznikami postępu, dążyli do ulepszania i udoskonalania środowiska człowieka z pomocą metody naukowej do rozwiązywania problemów społecznych, politycznych i ekonomicznych ${ }^{6}$. Dewey był często nazywany ojcem edukacji progresywistycznej, lecz tożsamość jego poglądów i koncepcji z edukacją progresywistyczną powinna być rozważana ostrożnie ${ }^{7}$.

\section{Podstawy filozoficzne pedagogiki pragmatyzmu}

Filozoficzne podstawy pedagogiki pragmatyzmu Deweya nawiązywały do wybitnych dokonań jego poprzedników. Pierwsze przesłanki filozofii progresywizmu przedstawił w swoich dziełach Charles Sanders Peirce (1839-1914), który „szukając skutecznych metod kształcenia jasności myśli, stwierdził, że jedynie taka wiedza o rzeczywistości zasługuje na zaufanie, która potrafi przewidywać poprawnie skutki określonych działań" ${ }^{8}$. Także William James (18421910) chciał, aby filozofia pragmatyzmu „pozwoliła ludziom myśleć i działać zgodnie z ich potrzebami, przy czym w ujęciu kryterium prawdy, dotyczy

7 G. L. Gutek, New Perspectives on Philosophy and Education, New Jersey 2009, s. 79.

8 Ch. S. Peirce, How to Make Our Ideas Clear, „Popular Science Monthly”, 12 (1878) s. 286-302. 
subiektywnego przekonania o potwierdzeniu się bądź też nie naszych przewidywań odnośnie do świata i wydarzeń"

Myśl pedagogiczna Deweya jest zatem „próbą przystosowania szkoły do potrzeb i wymagań nowoczesnego życia społecznego, stworzenia nowego typu wychowania, jako narzędzia społecznej przebudowy w kierunku twórczego, radykalnego demokratyzmu"10. W edukacji progresywizm zaznaczył się sprzeciwem wobec werbalizmu i autorytaryzmu, które cechowały ówczesny, a tradycyjny system kształcenia. Stanowisko tej ideologii edukacyjnej opiera się na stwierdzeniu, że „oprawa ludzkiej egzystencji i reform społeczeństwa są nie tylko możliwe, ale wręcz pożądane"11. Wśród przedstawicieli wspomnianego nurtu nie brakowało zarówno zwolenników, jak i przeciwników Deweyowskiego pragmatyzmu. Zwolennicy uważali, że „reforma szkolnictwa powinna być częścią zakrojonego na szeroką skalę procesu przemian obejmującego całość instytucji i stosunków społecznych" ${ }^{\prime 2}$. W swoich poglądach Dewey zgadzał się z wieloma elementami edukacji progresywistycznej, ale też odrzucał niektóre z nich.

Jako demokrata negował dogmaty o przyrodzonej hierarchii ludzi, z których część, w tym kapłani czy królowie, zostałaby predysponowana do wyznaczania prawdy i sprawowania władzy, podczas gddy reszta powinna się im podporządkować. Nie wszyscy jednak, którzy na przekór tym roszczeniom obwieszczali wolność lub równość jednostek, mogli być nazywani głosicielami demokracji. Zdaniem Deweya nieporozumieniem było uznanie atomistycznego indywidualizmu, znanego też pod nazwą laissez faire oraz niwelowanie różnic pomiędzy ludźmi w imię dobra ogółu, czego domagał się tzw. komunizm pierwotny. Obie teorie przyjmują za pewnik przeświadczenie, że jednostka i społeczeństwo są sobie przeciwstawne. Mamy bowiem do czynienia z binarnym podziałem, który, jak inne tego typu schematy, nie sprawdza się w rzeczywistości. Dewey stworzył teorię, która nie tylko domaga się demokracji czy tłumaczy jej zasady, ale jest wprost jej artykulacją. Warto jednak, aby „obecna sytuacja była rozpatrywana w całej swojej specyfice, a nie sztywno podciągana pod utrwalone koncepcje, wywiedzione z przeszłości"13.

9 B. Suchodolski, Wstęp, w: J. Dewey, Demokracja i wychowanie, Wprowadzenie do filozofii wychowania, tłum. Z. Doroszowa, wstęp B. Suchodolski, Wrocław 1972, s. XIII-XV.

10 L. Chmaj, Prądy i kierunki w pedagogice XX wieku, Warszawa 1962, s. 262.

11 Tamże.

12 G. L. Gutek, Filozofia dla pedagogów, s. 296.

13 J. Dewey, Renascent Liberalism, w: The Essential Dewey, t. 1, Pragmatism, Education, Democracy, eds L. A. Hickman, T. M. Alexander, Bloomington 1998, s. 332. 


\section{John Dewey i inni pedagodzy}

Joe Burnett, analizując wkład Deweya w edukację, przestrzega przed utożsamianiem jego eksperymentalizmu jedynie z progresywizmem pedagogicznym $^{14}$. Podwalin pod przyszły progresywizm należy szukać w naturalizmie Jean-Jacques Rousseau i jego wychowaniu do wolności oraz w teorii nauczania początkowego szwajcarskiego pedagoga Johanna Heinricha Pestalozziego. To Emil jako tytułowy bohater traktatu pedagogicznego Rousseau miał prawidłowo dojrzewać do wolności, oswajając się od najmłodszych lat ze swobodą i samodzielnością. Dziecko, które w niemowlęctwie nie było krępowane przez ciasne beciki ${ }^{15}$, okazywało się ruchliwe i ciekawe świata. Ważne, by nie spełniano jego zachcianek, ale utrwalano w nim minimalną zależność od innych przy jednoczesnej świadomości ograniczeń płynących ze świata rzeczy. Kiedy więc zbije okno, musi spać przy wybitym; kiedy zmoczy buty, sam dochodzi do wniosku, że prowadzi to do przeziębienia, a więc nieprzyjemności ${ }^{16}$.

Dobra znajomość prawidłowości występujących w naturze uczy Emila, jak radzić sobie samodzielnie, a innych prosić o pomoc jedynie wtedy, kiedy jest to konieczne. W ten sposób w dziecku wykształcają się cechy pozwalające przetrwać w niekorzystnych warunkach fizycznych, ale także, co ważniejsze, umiejętności uczenia się na własnych błędach i samodzielnego osądzania sytuacji, początkowo sterowane dyskretnie przez guwernera, bez zdawania się na sądy otoczenia. Chodziło jedynie o to, aby Emil zetknął się z żywiołem społecznym i wytwarzanymi przezeń hierarchiami, uważanymi przez Rousseau za niesprawiedliwe, odpowiednio późno, kiedy będzie na tyle silny psychicznie, aby oprzeć się stereotypom i uprzedzeniom. Dewey korzystał również z metody nauczania opracowanej przez Pestalozziego w zakresie formułowania precyzyjnych pojęć na podstawie percepcji zmysłowych. Szwajcarski reformator wychowania oparł poznawanie przedmiotów na ich opisywaniu przez dziecko.

14 J. Burnett, Whatever Happened to John Dewey?, w: Philosophy of Education since Mid Century, red. J. F. Soltis, New York 1981, s. 66-67.

15 Tak o tym pisze: „Czy więzy tak okrutne mogą pozostać bez wpływu na poczucie dzieci i na ich usposobienie? Pierwszym ich uczuciem jest uczucie bólu i cierpienia; znajdują one nieustanne przeszkody dla ruchów, których potrzebują [...] pierwszym darem, który od was otrzymują, są kajdany [...]"; J. J. Rousseau, Emil, czyli o wychowaniu, Virtualo 2015, s. 18.

16 Tamże, s. 100. 
Podobnie jest dzisiaj w Finlandii, gdzie dzieci same wracają ze szkoły już od pierwszych dni nauki w szkole podstawowej. Zdaniem rodziców, ma to wpływ na ich usamodzielnienie się. Dyrekcja szkoły „cieszy się, jak dzieci biegają na przerwach po korytarzu"17. Fińskie dzieci po szkole chodzą w kapciach, skarpetkach, na bosaka. Mają prawo być ruchliwe, mogą również popełniać błędy, np. biegają po korytarzu czy spadają ze schodów, ale - w przeciwieństwie do polskiej szkoły - dyrekcja i nauczyciele uważają to za zupełnie normalne zjawisko. W każdej fińskiej szkole słowo "zaufanie" wybrzmiewa w murach szkolnych, w klasach i postawach ludzkich, ponieważ oczywistym jest „zaufanie do nauczycieli, zaufanie do dzieci, zaufanie do rodziców i rodziców do szkoły"18. W Finlandii uczniowie uczą się na własnych błędach i stale uzyskują wsparcia ze strony nauczycieli, by mogli stawać się autonomicznymi jednostkami. Finlandia prowadzi na najwyższym poziomie zróżnicowane „poradnictwo przez całe życie szkolne uczniów, aby zapewnić im najwyższą jakość edukacji1 ${ }^{19}$.

\section{John Dewey i metody nauczania}

Na początku XX wieku John Dewey pisał w Experience and Education ${ }^{20}$, że spontaniczną siłą dzieci, która nie może być tłumiona, jest umiejętność wyrażania siebie. Dzieci posiadają własny, indywidualny zbiór doświadczeń. Ich zainteresowania wynikają z osobistych pobudek, a nie ze zbioru wiedzy i towarzyszących im faktów, koncepcji, uogólnień czy teorii. Ten twórca nowego kierunku w pedagogice chciał, aby nauczyciele dali dzieciom szansę gromadzenia doświadczeń i przekonali się, jak ukształtowały one ich wiedzę. Sugerował poszukiwanie impulsów, sytuacji (starting points), w wyniku których dziecko będzie naturalnie zainteresowane zdobywaniem wiedzy. Chciał, aby nauczyciele płynnie i dynamicznie organizowali dziecku doświadczenia, a więc żeby program nauczania był dostosowany do jego potrzeb i zaciekawień.

17 Finlandia: Dyrektor cieszy się, kiedy dzieci biegają po korytarzu. A u nas?, https:// www.edziecko.pl/Junior/7,160035,25389971, dostęp: 21.03.2021.

18 Tamże, s. 1.

19 Lifelong Guidance in Finland, http://www.cimo.fi/instancedata/prime_product_julkaisu/cimo/embeds/cimowwwstruc-ture/25493_Lifelong_guidance_in_Finland.pdf, s. 3, dostęp: 21.03.2017.

20 J. Dewey, Experience and Education, New York 1938. 
Projektowanie programów nauczania skoncentrowanych na dziecku (child-centered curriculum) rozwinęło się w latach dwudziestych i trzydziestych xx wieku, głównie dzięki pracom dwóch autorów. Ellsworth Collings wprowadził program nauczania skoncentrowany na dziecku uczęszczającym do szkół publicznych w hrabstwie McDonald w stanie Missouri, William Heard Kilpatrick zaś wdrożył metodę projektu w Lincoln School w York City ${ }^{21}$. Zanim to nastąpiło, Kilpatrick pracował metodą projektu (project method) stosowaną przez wiele dekad na University of Washington College of Education, dzięki grantowi przyznanemu mu przez rząd USA.

We współczesnym szkolnictwie fińskim stosuje się metodę opartą na doświadczaniu zjawisk (phenomenon-based learning), która jest bardzo zbliżona do uczenia się opartego na metodzie projektów (project-based learning). Jak sądzę, różnica dotyczy jedynie nazewnictwa. Oba podejścia - Collingsa i Kilpatricka uznają za priorytetowe prowadzenie zajęć praktycznych, które dadzą uczniom kontrolę nad ukierunkowaniem zadań projektowych. Obaj kładą nacisk na zadania związane z rzeczywistym światem. Stwarza to młodym ludziom większą swobodę w eksplorowaniu tematów, które uważają za najbardziej interesujące w ramach przyjętego tematu projektu. Warto zaznaczyć, że w Finlandii uczenie się problemowe (problem-based learning), jako bazujące na doświadczaniu zjawisk, ma interdyscyplinarny charakter. To oznacza, że powinno ono być wynikiem formułowania pytań przez uczniów. Powyższa metoda sprzyja realizacji fińskiej strategii reform programowych dla szkół podstawowych (National Core Curriculum for Basic Education 2014), zwracając szczególną uwagę na kształcenie transwersalnych kompetencji (transversal competences) ${ }^{22}$.

\section{Deweyowskie implikacje w wychowaniu i życiu szkoły fińskiej}

Dla Deweya istniał bliski związek między filozofią a wychowaniem. Wychowanie to laboratorium, w którym w wyniku filozoficznych analiz formułuje się cele kształcenia intelektualnego i moralnych zachowań, aby przygotować jednostkę

21 W. H. Kilpatrick, The Project Method, New York 1918, s. 319-335.

22 A. Suwalska, Transversal Competences in Physical Education in Finnish National Core Curriculum 2014 for Basic Education, „Annales Universitatis Mariae Curie-Skłodowska: Sectio J. Paedagogia-Psychologia", 34 (2021) nr 2, s. 83-94, DOI: 10.17951/j.2021.34.2.83-94. 
do swobodnego i aktywnego uczestniczenia w życiu społecznym. Wychowanie było dla Deweya „procesem wrastania jednostki w społeczną świadomość gatun$\mathrm{ku}^{\prime 23}$, procesem przekazywania jej intelektualnych i moralnych zasobów zdobytych przez ludzkość w toku rozwoju. Udoskonalenie społeczeństwa, a przez to powodzenie demokracji uzależniał ów pedagog właśnie od tego, w jakim stopniu wychowanie potrafi stworzyć "nowego człowieka”24, by był on twórczy i aktywny, potrafił sprostać nowym wyzwaniom i jeśli trzeba, przeorganizować swoje życie. Progresywiści skupieni w Progressive Education Association (organizacja założona w 1919 r. w Chicago) byli zdania, że wychowanie powinno umożliwić dziecku swobodny rozwój i dostarczać mu okazji do uczestniczenia w zajęciach wyrabiających samodzielność, kreatywność i zdolność wyrażania własnego Ja ${ }^{25}$. Nic dziwnego, że i dla Deweya życie szkoły czy klasy powinno odwzorowywać w miniaturze życie społeczne, dlatego szkoła ma umożliwiać dziecku stopniowe oswajanie się ze strukturą i zasadami funkcjonowania społeczności ludzkiej.

Co ciekawe, Deweyowskie myślenie o edukacji skoncentrowanej na dziecku (child-centred) zostało przyjęte przez Pasiego Sahlberga ${ }^{26}$ jako jednego z fińskich edukatorów nauczycieli. Wiele szkół fińskich zaadaptowało zasady demokratyczne zachęcając uczniów, aby samodzielnie podejmowali decyzje dotyczące własnego życia i wyboru przyszłego kierunku studiów. Zasady te zostały zawarte w fińskim programie nauczania już dla szkoły podstawowej. Jej program powinien być realizowany wokół „ludzkich impulsów do nawiązywania kontaktów towarzyskich, konstruowania, dociekania, kwestionowania, eksperymentowania oraz wyrażania czy tworzenia artystycznego" ${ }^{27}$. Skoro Dewey nie widział potrzeby podziału wiedzy na dziedziny akademickie, ale propagował organizowanie kształcenia wokół problemów naukowych i społecznych, toteż i programy kształcenia powinny temu odpowiadać (child-centered, experience-centered curriculum).

Podążając za tą sugestią, Finowie zapisali w National Core Curriculum for Basic Education 2014, że w „[...] opracowywaniu, planowaniu, wdrażaniu i stosowaniu curriculum dla szkół podstawowych trzeba uwzględnić świat przedmio-

23 L. Chmaj, Prądy i kierunki w pedagogice XX wieku, s. 252.

24 Tamże, s. 263.

25 G. L. Gutek, Filozofia dla pedagogów, s. 298.

26 P. Sahlberg, Finnish Lessons 2.o. What Can the World Learn from Educational Change in Finland?, New York-London 2015, s. 167.

27 Tamże. 
towy [...] należy uwzględnić ergonomię, walory ekologiczne, estetykę, warunki akustyczne, a także oświetlenie, jakość powietrza w pomieszczeniach, komfort i porządek w lokalu"28. Postulują zatem właściwe wykorzystanie szkoły, w tym mebli, usług bibliotecznych i sprzętu do wsparcia nauczycieli, aby skuteczniej mogli aktywizować uczniów w toku kształcenia. Według National Core Curriculum for Basic Education 2014 dobrze zorganizowane środowisko uczenia się sprzyja kształtowaniu pożądanych interakcji, uczestnictwu i wspólnemu budowaniu wiedzy. Wspomniane czynniki umożliwiają aktywną współpracę ze społecznościami lokalnymi oraz ekspertami spoza szkoły.

\section{Eksperymentalizm Johna Deweya i jego implikacje w szkole fińskiej}

$\mathrm{Na}$ poglądach wielu progresywistów fińskich zaważył eksperymentalizm Deweya, którego podstawę stanowiła koncepcja wychowania uspołeczniającego. Pedagog rozumiał myślenie i działanie jako jednolity przepływ doświadczeń społecznych. Myślenie pozostaje niepełne, dopóki nie zostanie zweryfikowane za pomocą doświadczenia. Podkreślał, podobnie jak wielu pedagogów progresywnych, znaczenie doświadczeń, ich ciągłości oraz konieczności rozwijania zainteresowań dziecka i zaspokajania jego potrzeb. Jednocześnie krytykował sentymentalnych, romantycznych progresywistów, którzy w myśl filozofii Rousseau głosili potrzebę skupienia się wyłącznie na dziecku ${ }^{29}$.

Dewey krytykował istotę edukacji tradycyjnej, polegającej na odgórnym narzucaniu szkołom treści oraz metod kształcenia. Taka edukacja, oderwana od praktycznych, codziennych doświadczeń dzieci sprawiała, że zmiana w świecie stawała się czymś wyjątkowym, a nie regułą ${ }^{30}$. Szkoła tradycyjna, jak twierdził amerykański pedagog, to instytucja formalna, w której kształcenie odbywa się według programu nauczania opartego na treściach przedmiotowych takich dyscyplin, jak język, historia, matematyka i nauki przyrodnicze. Rozwój nowej „myśli z początkiem bieżącego stulecia wywołał skutki nieoczekiwane, gdyż nie tylko obalił podstawy starej szkoły, jej formalizm i werbalizm, usunął wrogi stosunek do indywidualności ucznia i obojętność dla konkretnego, otaczającego szkołę

28 Tamże, s. 40.

29 G. L. Gutek, Filozofia dla pedagogów, s. 90.

30 Tamże, s. 5. 
życia"31. Przyczynił się także do powstania wielu prób reformistycznych i szkół eksperymentalnych, zmieniając zasadniczo atmosferę wychowawczą klas i szkół. W latach 1894-1904 Dewey założył w Chicago Szkołę Eksperymentalną, w której stworzył poligon doświadczalny służący testowaniu jego filozofii kształcenia. Pisał, że szkoła ta „[...] została pomyślana, jako laboratorium. Odgrywa w pracy pedagoga taką samą rolę, jak laboratorium w pracy biologa, fizyka czy chemika. Jak wszystkie laboratoria powinna spełniać dwa zadania: umożliwić formułowanie, testowanie, weryfikowanie i obalanie hipotez i reguł oraz dostarczać materiału wzbogacającego zbiór znanych faktów i reguł"32.

Chcąc sprostać wymaganiom XXI wieku, Finowie zaproponowali wieloprzedmiotowe moduły edukacyjne (multidisciplinary learning modules) ${ }^{33}$, które mają zastosowanie już w szkole podstawowej. Promują one osiąganie celów wyznaczonych dla poziomu podstawowego, w szczególności rozwój kompetencji transwersalnych (transversal competences ${ }^{34}$ ). Tematyka modułów jest planowana lokalnie, aby mogła odzwierciedlać zasady kultury konkretnej szkoły oraz sprzyjać doskonaleniu współpracy między szkołą a otaczającą ją społecznością. Aktualne i lokalne treści modułów sprzyjają tworzeniu więzi społecznych, a poza tym zwiększają motywację nauczycieli i uczniów. Zgodnie z koncepcją eksperymentalizmu Deweya niezbędne jest uczestniczenie uczniów w planowaniu eksperymentu, toteż w edukacji fińskiej postulat ten zaowocował opracowaniem wieloprzedmiotowych modułów ${ }^{35}$.

Według National Core Curriculum for Basic Education $2014^{36}$ planowanie modułów w fińskiej szkole pozwala uczniom wybierać tematykę ważną z ich punktu widzenia, a nauczycielom pracować z uczniami w grupach heterogenicznych wiekowo. Następuje tu proces łączenia aktualnej wiedzy ucznia z wiedzą i umiejętnościami nabytymi w szkole. Moduły wieloprzedmiotowe sprzyjają budowaniu przestrzeni budzenia intelektualnej ciekawości, realizacji doświadczeń i kreatywności uczniów, a zarazem są dla nich wyzwaniem. Moduły te uruchamiają różnego rodzaju interakcje i generują sytuacje, które związane są

31 L. Chmaj, Prądy i kierunki w pedagogice XX wieku, s. 7.

32 Tamże, s. 86.

33 National Core Curriculum for Basic Education 2014, Helsinki 2016, s. 32-34.

34 A. Suwalska, Transversal Competences, s. 83-94.

35 Tamże, s. 33.

36 Tamże. 
z używaniem języka, wzmacniają zastosowanie wiedzy i umiejętności w praktyce, a tym samym kształtują zrównoważony styl życia.

\section{Pedeutologiczne i psychospołeczne implikacje progresywizmu w szkole fińskiej}

Filozoficzne przesłanki Deweya znajdują bezpośrednie zastosowanie we współczesnej edukacji fińskiej. Teorie edukacyjne i kształcenie nauczycieli są oparte na badaniach naukowych, metodyce badań i codziennej praktyce pedagogicznej, wyznaczając główne kierunki rozwoju zawodowego nauczycieli. Fińscy nauczyciele podczas studiów i po ich ukończeniu uczą się, jak projektować, przeprowadzić i prezentować najbardziej oryginalne zadania teoretyczne i praktyczne. Poza tym kluczowe w przygotowaniu zawodowym przyszłych nauczycieli są praktyczne szkolenia odbywane w szkołach podczas studiów uniwersyteckich. Według Sahlberga ${ }^{37}$ nauczyciele rozumieją nauczanie jako proces całościowy i w tym wymiarze doskonalą swoją pracę. Zgodnie z teorią koncepcji kontinuum doświadczeniowego doskonalą kompetencje zawodowe przez cały okres pracy zawodowej.

W kulturze fińskiej zawód nauczyciela jest postrzegany jako jeden z najważniejszych zawodów w społeczeństwie. Wysoki status nauczyciela wpływa na nauczycielską autonomię. Dzięki temu nauczyciel ma możliwość pracy na przygotowanych przez siebie materiałach edukacyjnych ${ }^{38}$. Autonomię nauczyciela można również dostrzec w suwerennym stosowaniu przez niego metod kształcenia i oceniania. Wolność i odpowiedzialność pedagogiczna stanowią istotne cechy fińskiej edukacji1 ${ }^{39}$. Dzisiaj jest już sprawą oczywistą, że autonomia nauczycieli fińskich miała wpływ na zwiększenie autonomii uczniów ${ }^{40}$.

\section{P. Sahlberg, Finnish Lessons 2.o.}

38 H. Heo i in., Exploring Learning Culture in Finnish and South Korean Classrooms, „The Journal of Educational Research", 111 (2018) nr 4, s. 463, DoI:10.1080/00220671.20 17.1297924 .

39 A. Toom, J. Husu, Finnish Teachers as "Makers of the Many", w: Miracle of Education: The Principles and Practices of Teaching and Learning in Finnish Schools, red. H. Niemi, A. Toom, A. Kallioniemi, Rotterdam 2012, s. 39-54.

40 H. Teräs i in., Learning Cultures and Multiculturalism: Authentic E-Learning Designs, w: Multicultural Awareness and Technology in Higher Education: Global Perspectives, red. T. Issa, P. Isaias, P. Kommers, Hershey, PA 2014, s. 197-217, DOI: 10.4018/978-1-4666-5876-9. 
Ponadto takie wartości jak równość w dostępie do edukacji, współpraca i zaufanie do siebie nauczycieli i nauczycieli do uczniów są postrzegane jako filary uczenia się w edukacji podstawowej ${ }^{41}$. Wartości te, wpisane w koncepcję uczenia się, pomagają uczniom doskonalić umiejętność bieżącego uczenia się oraz stanowią wkład do kształcenia ustawicznego, uczynienia z kształcenia stylu życia.

$\mathrm{W}$ istocie to wartości rzutują na wysoki poziom samooceny, poczucie własnej skuteczności i sprawczości fińskich uczniów ${ }^{42}$. Fundamentalne w fińskiej edukacji wartości zostały wpisane do National Core Curriculum for Basic Education. Są wśród nich m.in.: prawo każdego dziecka do dobrej edukacji i prawo do rozwoju w ramach demokratycznego społeczeństwa, a w konsekwencji - kształtowania wartościowego życia. Wychowanie podstawowe w Finlandii ma wpływ na uczenie się, co sprzyja interakcji pomiędzy różnymi kulturami w świetle zrównoważonego rozwoju i wiedzy ekospołecznej. Uczniowie są przygotowywani do podejmowania decyzji, które mają wpływ na całe ich życie. Uczą się okazywania szacunku innym ludziom. Normy zachowania i uczenie się w konsekwencji zachęcają do długich dyskusji w szkole na temat ogólnej odpowiedzialności za Ziemię i godność człowieka. Ponadto podstawowe wartości edukacyjne promują równość gospodarczą, społeczną, regionalną i równość płci.

Fińska szkoła realizuje zatem idee amerykańskich progresywistów, którzy wskazywali na wartość współpracy nauczycieli, rodziców i szkoły w celu zaspokajania potrzeb dzieci w toku ich rozwoju. Finlandia wypracowała sprawiedliwy i nieselektywny system edukacji, w którym wszystkim uczniom zapewnia się ten sam rodzaj powszechnego kształcenia ${ }^{43}$. Nauczyciele cieszą się zaufaniem ${ }^{44}$, gdyż postrzega się ich jako prawdziwych profesjonalistów w dziedzinie edukacji. Nauczyciel progresywistyczny powinien pomagać dziecku w nauce i sterować jego działalnością badawczą, a nie narzucać mu swojego zadania. Co więcej, progresywiści zgadzali się z Dewey co do testowania innowacyjnych technik ${ }^{45}$

41 A. Suwalska, Values and Their Influence on Learning in Basic Education in Finland- Selected Aspects, „Roczniki Pedagogiczne”, 13 (2021) nr 2, s. 141-154, DOI: 10.18290/rped21132.10.

42 National Core Curriculum for Basic Education 2014, s. 15.

43 J. Vaalijearvi i in., The Finnish Success in Pisa - and Some Reasons Behind It, Jyvaaskyla 2007, https://ktl.jyu.fi/jul, dostęp: 07.02.18.

44 A. Suwalska, High-trust to Teachers' Job in Finland after 1970s, „Studia z Teorii Wychowania", 9 (2019) nr 3, s. 273-286.

45 P. A. Graham, Progressive Education Association: From Arcady to Academy. A History of the Progressive Education Association 1919-1955, New York 1961. 
oraz twierdzenia, że ocena osiągnięć ucznia powinna uwzględniać postępy, jakie zrobił w rozwoju umysłowym, fizycznym, moralnym i społecznym.

W fińskiej szkole podstawowej widoczna jest wszechstronna współpraca pomiędzy administratorami, nauczycielami, rodzicami i placówką. Ma ona służyć rozwiązywaniu problemów i radzeniu sobie z wyzwaniami współczesności. Wpływa także na kulturę uczenia się rozumianą jako zbiór wspólnych przekonań, wartości i postaw sprzyjających edukacji ${ }^{46}$. Nauka jest powiązana z kulturą uczenia się szkoły ${ }^{47}$, która wpisuje się w kontekst społeczny i kulturowy na poziomie regionalnym i krajowym ${ }^{48}$. Prawdziwy pedagog powinien uwzględniać czynniki wewnętrzne, które warunkują doświadczenia ucznia, jego potrzeby, zainteresowania, cele, zdolności i dążenia oraz łączyć je z czynnikami środowiskowymi o charakterze historycznym, fizycznym, ekonomicznym i społecznym.

Dewey twierdził, że progresywistyczny nauczyciel nie może w sposób naiwny idealizować natury dziecka i zaspokajać jego potrzeb, gdyż takie podejście nie stanowi ostatecznego celu uczenia się. Dziecięce „instynkty i popędy należy odpowiednio ukierunkować tak, aby w nauczaniu skupić się na tych popędach, które pobudzają do refleksji polegającej na ocenie konsekwencji działania podjętego pod ich wpływem" ${ }^{\text {"49 }}$. Uczeń, który szuka sposobu „na osiągniecie celu", wyobraża sobie przyszłe rezultaty swoich poczynań. Umiejętność przewidywania skutków określonego działania uczy konsekwencji podobnych działan, które będą podejmowane w przyszłości. Dlatego zadaniem edukacji progresywistycznej powinno być „wyrobienie u uczniów nawyku refleksyjnej analizy celów i sposobów ich osiągania"50.

W związku ze złożonym i skomplikowanym życiem społecznym ważne jest, aby dziecko mogło nawiązać z nauczycielem bezpośredni kontakt „bez rozproszenia sił i wewnętrznego rozbicia". Z tego też powodu Dewey wyróżnił trzy podstawowe zadania szkoły. Pierwszym jest upraszczanie życia społecznego poprzez

46 Innovative Workplaces: Making Better Use of Skills Within Organizations, Paris 2010, http://www.oecd-ilibrary.org/education/innovative-workplaces_9789264095687-en, dostęp: 07.02.2018.

47 A. Suwalska, Culture of Teaching in Finnish Schools in Context of Educational Change, „Polish Journal of Educational Studies”, 71 (2018) nr 1, s. 112-122, DOI: 0.2478/ poljes-2018-0010.

48 M. Osborn i in., A World of Difference? Comparing Learners Across Europe, Berkshire 2003.

49 G. L. Gutek, Filozofia dla pedagogów, s. 300.

50 Tamże. 
wybór form podstawowych, najbardziej odpowiednich do doświadczeń i zdolności dziecka. Drugim jest poszukiwanie przykładów oddziaływujących na dziecko w celu przekazania tylko cech wartościowych społecznie. Trzecim zadaniem szkoły jest zespalanie w umyśle dziecka różnorodnych wpływów środowisk społecznych, aby umożliwić jednostce życie w każdej grupie społecznej.

Dewey twierdził, że najskuteczniejszym czynnikiem postępu społecznego i demokratycznego społeczeństwa jest szkoła i zatrudnieni w niej nauczyciele. Nie chodzi tylko o kształcenie jednostek, ale też o przygotowanie ich do życia społecznego, a w konsekwencji przyczynienie się do właściwego postępu społecznego. W tym właśnie upatruje Dewey istotę powołania nauczycielskiego ${ }^{51}$. Trzy powyższe zadania realizuje w XXI wieku fińska szkoła, co wpisuje się w szeroko zaplanowane zmiany edukacyjne.

\section{Podsumowanie}

Podstawą polityki oświatowej powinien być progresywizm jako filozofia, która bazuje na doświadczeniu pojmowanym jako rezultat interakcji człowieka ze środowiskiem. Najważniejszą cechą takiego podejścia jest fakt, że cele kształcenia nie są zewnętrzne, czyli narzucane odgórnie. Skoro edukacja ma być procesem prowadzącym do rozwoju każdej jednostki ludzkiej, to powinna polegać na zdobywaniu przez nią nowych doświadczeń, które pociągną za sobą następne doświadczenia i pozwolą sprawować nad nimi kontrolę. Równocześnie prawdziwa edukacja progresywistyczna nie może odcinać się od przeszłości, ale powinna wykorzystywać ją do rekonstrukcji bieżących doświadczeń i ukierunkowywania przyszłych. Dewey opierał swoją teorię edukacji na koncepcji kontinuum doświadczeniowego - ciągu następujących po sobie doświadczeń, w którym przeszłość łączy się z teraźniejszością i umożliwia kształtowanie przyszłości.

Powyższe poglądy doskonale odzwierciedlają zmiany edukacyjne w fińskiej szkole zakładającej uczenie się oparte na doświadczaniu zjawisk (phenomenon-based learning), na realizacji programu kształcenia metodą projektów (project-based learning) oraz na kształceniu problemowym (problem-based learning). Powyższe metody sprzyjają realizacji fińskiej strategii reform reali-

51 L. Chmaj, Prądy i kierunki w pedagogice XX wieku, s. 262. 
zowanej w ramach przyjętego w 2014 r. Programu Nauczania dla szkoły podstawowej. Chcąc sprostać wymaganiom XXI wieku, wprowadzono już do szkół podstawowych wieloprzedmiotowe moduły kształcenia (multidisciplinary learning modules). Sprzyjają one rozwojowi kompetencji transwersalnych (transversal competences). Ponadto wychowanie w tym typie szkół ma wpływ na uczenie się, gdyż odwołuje się do idei zrównoważonego rozwoju i wiedzy ekospołecznej. Uczniowie potrafią okazywać szacunek innym ludziom, uczą się również, jak podejmować decyzje, które mają wpływ na całe ich życie.

W powyższej pracy ukazano wpływ i znaczenie założeń wybitnego filozofa progresywisty i pragmatysty Deweya na myśl pedagogiczną fińskich pedagogów na przełomie XX i XXI wieku. Podane druzgoczącej krytyce zasady dawnego wychowania pozwoliły inaczej spojrzeć na psychikę i wychowanie dziecka oraz przekształcać szkołę w żywą instytucję, która odwołuje się do doświadczeń w kształceniu i wprowadza zajęcia praktyczne z zastosowaniem środków poglądowych, m.in. w naukach przyrodniczych i nauczaniu historii. Wyniki uczniów szkół eksperymentalnych utwierdziły go w przekonaniu, że każda idea jest na tyle wartościowa, na ile „służy człowiekowi jako narzędzie swobodnego i aktywnego uczestniczenia w życiu społecznym" ${ }^{\prime \prime 2}$ i ułatwia mu przystosowanie się do wyzwań, przed jakimi staje obywatel każdego społeczeństwa. Z perspektywy fińskich uczniów idealnie wpisują się w przygotowanie do życia w „globalnej wiosce" słowa Silandera wskazujące na to, że nauczyciele nie przygotowują uczniów „do egzaminów PISA, ale przygotowują ich do życia”"53.

W świetle powyższego warto chyba wykorzystać powinność pracy metodą projektu w polskich gimnazjach w ponownie zreformowanej szkole, by dobrze służyła do efektywnego przygotowania pokolenia młodych Polaków do życia w rozwijającym się społeczeństwie wiedzy i ustawicznego oraz aktywnego uczenia się.

Streszczenie: Myśl pedagogiczna Johna Deweya była próbą sprzeciwu wobec tradycyjnego systemu kształcenia, a jednocześnie przystosowania szkoły do potrzeb i wymagań nowoczesnego życia społecznego i stworzenia nowego typu wychowania. W artykule przedstawiono również wątki biograficzne i pedagogiczne z życia Johna Deweya mające wpływ na zmiany edukacyjne dokonane w podstawowej edukacji fińskiej.

52 Tamże, s. 251.

53 P. Silander, How to Create the School of the Future, Helsinki 2017. 
Słowa kluczowe: John Dewey, implikacje pedagogiczne, progresywizm, pragmatyzm, eksperymentalizm, wychowanie, fińska edukacja podstawowa, krytyka szkoły tradycyjnej, wieloprzedmiotowe modele kształcenia.

\section{Bibliografia}

Burnett J., Whatever Happened to John Dewey?, w: Philosophy of Education Since Mid Century, red. J. F. Soltis, New York 1981.

Chmaj L., Prądy i kierunki w pedagogice XX wieku, Warszawa 1962.

Dewey J., Education and Experience, New York 1958.

Dewey J., Renascent Liberalism, w: The Essential Dewey, t. I: Pragmatism, Education, Democracy, eds L. A. Hickman, T. M. Alexander, Bloomington 1998.

Dewey J., Demokracja i wychowanie. Wprowadzenie do filozofii wychowania, thum. Z. Doroszowa; wstęp B. Suchodolski, Wrocław 1972.

Graham P. A., Progressive Education Association, From Arcady to Academy. A History of the Progressive Education Association, 1919-1955, New York 1961.

Gutek G L., Filozofia dla pedagogów, tłum. A. Kacmajor i A. Sulak; posł. B. Śliwerski, Gdańsk 2007.

Gutek G. L., New Perspectives on Philosophy and Education, New Jersey 2009.

Heo H., Leppisaari I., Lee O., Exploring Learning Culture in Finnish and South Korean Classrooms, „The Journal of Educational Research", 111 (2018) nr 4, s. 459-472, DoI:10. 1080/00220671.2017.1297924.

Kilpatrick W. H., The Project Method, New York 1922.

National Core Curriculum for Basic Education 2014, Helsinki 2016.

Osborn M., Broadfoor P., McNess E., Planel C., Raven B., Triggs P., A World of Difference? Comparing Learners across Europe, Berkshire 2003.

Peirce Ch. S., How to Make our Ideas Clear, „Popular Science Monthly”, 12 (1878) s. 286-302.

Power E. J., Philosophy of Education, Studies in Philosophies, Schooling and Education Policies, New Jersey 1982.

Rousseau J. J., Emil, czyli o wychowaniu, Virtualo 2015, e-book.

Sahlberg, P., Finnish Lessons 2.O, What Can the World Learn from Educational Change in Finland?, New York - London 2015.

Suchodolski B., Wstęp, w: J. Dewey, Demokracja i wychowanie. Wprowadzenie do filozofii wychowania, tłum. Z. Doroszowa; wstęp B. Suchodolski, Wrocław 1972, s. XIII-XV.

Suwalska A., Culture of Teaching in Finnish Schools in Context of Educational Change, „Polish Journal of Educational Studies”, 71 (2018) nr 1, s. 112-122, DOI: 0.2478 / poljes-2018-0010.. 
Suwalska A., Values and Their Influence on Learning in Basic Education in FinlandSelected Aspects, „Roczniki Pedagogiczne”, 13 (2021) nr 2, s. 141-154, DOI: 10.18290/ rped21132.10.

Suwalska A., Transversal Competences in Physical Education in Finnish National Core Curriculum 2014 for Basic Education, „Annales Universitatis Mariae Curie-Skłodowska: Sectio J", 34 (2021) nr 2, s. 83-94, DOI: 10.17951/j.2021.34.2.83-94.

Suwalska A., High-trust to Teachers' Job in Finland after 1970s, "Studia z Teorii Wychowania", 9 (2019) nr 3, s. 273-286.

Teräs H., Leppisaari I., Teräs M., Herrington J., Learning Cultures and Multiculturalism: Authentic E-Learning Designs, w: Multicultural Awareness and Technology in Higher Education: Global Perspectives, red. T. Issa, P. Isaias, P. Kommers, Hershey, PA 2014, s. 197-217, DOI: 10.4018/978-1-4666-5876-9.

Toom A., Husu J., Finnish Teachers as "Makers of the Many", w: Miracle of Education: The principles and Practices of Teaching and Learning in Finnish Schools, red. H. Niemi, A. Toom, \& A. Kallioniemi, Rotterdam 2012, s. 39-54.

Whitman W., Poezje, tłum. S. Napierski, Torun 1996.

Finlandia: Dyrektor cieszy się, kiedy dzieci biegają po korytarzu. A u nas?, https://www. edziecko.pl/Junior/7,160035,25389971.

Lifelong Guidance in Finland, http://www.cimo.fi/instancedata/prime_product_julkaisu/cimo/embeds/cimowwwstruc-ture/25493_Lifelong_guidance_in_Finland.pdf, s. 3,

Innovative Workplaces: Making Better Use of Skills Within Organizations, Paris 2010, http://www.oecd-ilibrary.org/education/innovative-workplaces_9789264095687-en.

Vaalijearvi J., Kupari P., Linnakyla P., Reinikainen P., Sulkunen S.,Teornroos J., Arrfman I., The Finnish Success in Pisa - and Some Reasons Behind it 2, Jyvaaskylaa 2007, https://ktl.jyu.fi/jul kaisut/julkaisuluettelo/julkaisut/2007/do84. 